\title{
Strategi Cyber Public Relatons dalam Memanfaatkan Media Sosial untuk Membangun Citra Perusahaan
}

\author{
Rosliana dan Riris Loisa \\ mariamariaalie@gmail.com, ririsl@fikom.untar.ac.id
}

Fakultas Ilmu Komunikasi Universitas Tarumanagara

\begin{abstract}
This study discusses about the cyber public relations strategy while using social media for gaining corporate reputation. This study was conducted using case study analysis method with qualitative descriptive approach. The data used in this study were primary data and secondary data. The primary data comes from interviews conducted with informants, namely Billy Gani as Eannovate Creative Technology's CEO, Daud Julio \& Isabela Beatrix as Eannovate's workers who get the job from social media. While the secondary data was in the form of a coding table from the interviewee's answer. The results of this study are Eannovate Creative Technology using public relations strategy on social media. Eannovate Creative Technology has run the strategy by using Instagram and Facebook as the media to engage with public and gaining reputation. The following step that Eannovate used can be categorized into the Strategy of Public Relations described by Ronald D. Smith. The following steps is Formative research and Strategy (Establishing Goals and Objectives). Furthermore, the social media function used by PT Eannovate Creative Technology is suitable with Usman Hamid's theory, as a tool for information and interaction.
\end{abstract}

Keywords: Public Relations strategy, Social Media, Cyber Public Relations

\begin{abstract}
Abstrak
Penelitian ini membahas tentang strategi cyber public relations yang digunakan dalam media sosial untuk membangun citra perusahaan. Penelitian ini dilakukan dengan menggunakan pendekatan kualitatif deskriptif dan metodi studi kasus. Data yang digunakan dalam penelitian ini merupakan data primer dan data sekunder. Data primer didapatkan berasal dari hasil wawancara dengan Billy Gani sebagai CEO PT Eannovate Creative Technology, Daud Julio dan Isabela Beatrix sebagai karyawan dari PT Eannovate Creative Technology yang mendapatkan pekerjaannnya melalui media sosial. Sementara itu, data sekunder didapatkan dari hasil tabel koding jawaban wawancara narasumber. Hasil dari penelitian ini adalah PT Eannovate Creative Technology menjalankan strategi cyber public relations dengan menggunakan Instagram dan Facebook sebagai media untuk membangun citra perusahaan dan mendekatkan diri dengan publik. Tahapan yang digunakan oleh PT Eannovate Creative Technology dapat dikategorikan ke dalam tahapan strategi public relations yang dipaparkan oleh Ronald D. Smith yaitu tahapan Formative research dan Strategy (Establishing Goals and Objectives). Selain itu, penulis juga menemukan bahwa fungsi media sosial yang dijalankan oleh PT Eannovate Creative Technology sesuai dengan paparan dari Usman Hamid yaitu sebagai alat informasi dan interaksi.
\end{abstract}

\section{Pendahuluan}

Teknologi yang berkembang pada zaman globalisasi saat ini, membuat masyarakat, khususnya yang berada di daerah perkotaan semakin terbuka. Hal ini disebabkan karena kebutuhan manusia akan informasi yang instan dan mudah untuk didapat. Penggunaan teknologi untuk kegiatan sehari-hari sudah menjadi hal yang dianggap wajar bagi banyak orang. Pesatnya perkembangan teknologi tanpa sadar 
telah mengubah cara hidup kita, baik terhadap cara berkomunikasi, cara belajar, cara bekerja, cara berbisnis. Dapat disimpulkan bahwa perkembangan teknologi memberikan kenyamanan yang lebih dalam memberikan manusia kemudahan untuk mengelola dan menikmati kehidupannya.

Perkembangan teknologi saat ini juga didukung dengan kehadiran internet yang telah menciptakan perubahan besar dalam dunia informasi dan komunikasi. Dengan hadirnya internet, manusia dapat lebih mudah mengakses suatu informasi dan memperlancar komunikasi antar individu. Sifat internet yang interaktif membuat manusia lebih mudah untuk mengekspresikan diri, berkolaborasi, berpartisipasi dengan orang lain secara instan.

Keinginan manusia untuk mengakses informasi telah menjadi salah satu kebutuhan primer dari setiap orang. Hal ini disebabkan karena adanya informasi, hiburan, pendidikan, dan pengetahuan yang berasal dari seluruh belahan dunia dan tidak dapat diperoleh melalui media konvensional. Pesatnya perkembangan teknologi dan informasi serta semakin canggihnya perangkat-perangkat yang diproduksi oleh industri seperti menghadirkan "dunia dalam genggaman." Istilah ini sejajar dengan apa yang diutarakan oleh Thomas L. Friedman (2007) sebagai the world is flat, bahwa dunia semakin rata dan setiap orang bisa mengakses apa pun dari sumber mana pun.

Kebutuhan manusia untuk menjalin hubungan sosial melalui internet merupakan alasan utama yang dilakukan oleh khalayak dalam mengakses media. Hal ini merupakan salah satu hal yang tidak dapat diperoleh dari penggunaan media kovensional. Maka dari itu, tidak heran bahwa kehadiran internet dan media sosial menjadi cukup fenomenal.

Begitu pula dengan perusahaan. Dengan adanya perkembangan teknologi, internet, dan juga media sosial, perusahaan juga merasakan dampak terlebih dalam kegiatan pemasaran dan promosi. Sebuah perusahaan harus dapat menyebarkan dan menerima informasi agar dapat bersaing dengan perusahaan lainnya. Hal ini membuat persaingan antar perusahaan semakin kuat, baik bersaing dengan perusahaan baru lainnya, dan bersaing dengan perusahaan yang telah lama berdiri.

Internet telah mengubah cara perusahaan dalam mengimplementasikan keseluruhan strategi bisnis dan pemasaran yang dilakukan. Internet merupakan salah satu anak teknologi yang bertujuan untuk semakin mempermudah kehidupan manusia. Melalui internet yang merupakan bagian dari teknologi online, banyak tugas dari PR yang dapat terbantu.

Praktisi PR dapat melakukan komunikasi dengan publiknya tanpa harus bertemu secara langsung. Dengan demikian, secara tidak langsung, praktisi PR dalam perusahaan harus dapat menyesuaikan pesatnya perkembangan teknologi ini. Sifat internet yang fleksibel dan dinamis kerap dimanfaatkan perusahaan dalam menjalankan program-program public relations $(\mathrm{PR})$.

Salah satu cara yang tepat yang diambil oleh PR perusahaan adalah memanfaatkan internet dan media sosial sebagai salah satu platform untuk memperkenalkan dan menyebarluaskan informasi yang berkaitan dengan perusahaan kepada masyarakat. Tanpa adanya promosi dan publikasi, perusahaan akan mengalami kesulitan dalam mencari calon konsumen.

Oleh karena itu, tugas dari seorang praktisi PR dalam perusahaan adalah memastikan bahwa kegiatan promosi dapat menjangkau seluruh calon konsumen secara menyeluruh yang salah satunya dapat diraih melalui internet dan media sosial. 
Rosliana dan Riris Loisa: Strategi Cyber Public Relatons dalam Memanfaatkan Media Sosial untuk Membangun Citra Perusahaan

Penelitian ini dilakukan dengan menggunakan rumusan masalah yaitu "Bagaimana strategi cyber public relations yang dilakukan oleh perusahaan dalam memanfaatkan media sosial untuk membangun citra perusahaan?" yang bertujuan untuk mengetahui strategi cyber public relations dalam media sosial untuk membangun citra PT Eannovate Creative Technology.

\section{Metode Penelitian}

Jenis penelitian yang akan digunakan dalam menyusun penelitian ini adalah menggunakan pendekatan kualitatif atau induktif. Penelitian yang akan dilakukan penulis berhubungan dengan media sosial. Pada proses penelitian ini, peneliti secara langsung terlibat dan terjun langsung dalam kegiatan pengumpulan data guna melengkapi data yang dibutuhkan dalam menunjang hasil akhir penelitian.

Penelitian ini menggunakan pendekatan studi kasus sebagai bagian dari penelitian kualitatif. Yin (2011:1) mengatakan studi kasus adalah sebuah penyelidikan empiris yang menginvestigasi fenomena kontemporer dalam konteks kehidupan nyata, khususnya ketika batas antara fenomena dan konteks tidak begitu jelas. Metode pengumpulan data yang penulis lakukan adalah dengan melakukan wawancara dengan key informan dan observasi pada lokasi penelitian dan penelusuran melalui buku-buku tertentu serta sumber online.

Terdapat dua jenis data yang penulis gunakan dalam penelitian ini yaitu data primer dan data sekunder. Data primer berupa data yang didapatkan dari hasil wawancara key informan dan kedua narasumber lainnya. Sedangkan data sekunder didapatkan dari hasil analisis penulis terhadap jawaban key informan dan narasumber yang dikaitkan dengan tabel koding dan teori strategi public relations oleh Ronald D. Smith.

\section{Hasil Temuan dan Diskusi}

Tujuan utama dari praktisi public relations adalah menyebarkan informasi, menciptakan,memelihara, dan membina hubungan baik dengan masyarakat agar mendapatkan citra positif terhadap perusahaan.

Ronald D. Smith (2005) menjabarkan bahwa ada tahapan dalam strategi public relations yaitu Formative Research, Strategy, Tactics, dan Evaluative Research.

Fase pertama dalam proses perencanaan strategis adalah riset formatif atau riset stategis yang merupakan kegiatan pendahuluan untuk mendapatkan informasi dan menganalisa situasi yang dihadapi . Dalam fase ini terdapat tiga tahap yaitu:

a. Analyzing the situation

Merupakan proses awal penentuan strategi. Tahap ini digunakan untuk mengumpulkan semua informasi dan sekaligus menganalisa situasi.

Hal ini selaras dengan hasil analisis wawancara penulis dengan Key Informan, Billy Gani selaku CEO PT Eannovate Creative Technology yang menjelaskan mengenai strategi public relations yang digunakan yaitu selalu mengidentifikasikan jejaring media sosial baru yang digunakan oleh target audience, memposting layanan preview dari hasil pekerjaan dan lowongan serta aktivitas perusahaan.

Setelah itu, fase selanjutnya yang dilakukan oleh PT Eannovate Creative Technology adalah:

b. Analyzing the public 
Tahap ini dilakukan untuk mengidentifikasikan dan menganalisa publik yang menjadi sasaran. Hal ini akan membuat perusahaan mampu mengatur prioritas dalam berhubungan dengan pubilknya yang beragam. PT Eannovate membagi sasaran audience mereka menjadi 3 yaitu potensial klien, potensial karyawan tetap dan magang, dan potensial partner.

Setelah mengidentifikasikan situasi dan sasaran, target perusahaan yang ingin dicapai adalah menyebarkan informasi sebanyak mungkin kepada sasaran pasar sesuai dengan konten berdasarkan View, Reaction, Action dari Key Performance Index (KPI) yang sudah dibuat oleh divisi public relations untuk penyebaran dalam media sosial. Hal ini sesuai dengan strategi public relations selanjutnya yaitu:

a. Establishing goals and objectives

Tahap ini membuat perusahaan mengembangkan objektif yang jelas, spesifik dan terukur (measurable) sesuai dengan yang diinginkan perusahaan.

Key Performance Indicator (KPI) atau disebut juga sebagai Key Success Indicator (KSI) adalah satu set ukuran kuantitatif yang digunakan perusahaan atau industri untuk mengukur atau membandingkan kinerja dalam hal memenuhi tujuan strategis dan operasional mereka.

Perkembangan teknologi komunikasi memungkinkan penggunaan berbagai macam media untuk menyampaikan pesan. Salah satu media baru yang digunakan pada saat ini adalah internet. Dalam masa ini praktisi public relations tidak mengakses informasi melalui internet dianggap ketinggalan jaman, karena pemanfaatan internet dapat menambah variasi media informasi untuk publik, yang artinya penyebaran informasi yang diberikan tidak monoton. (Kriyantono, 2008:255).

Kebutuhan manusia untuk menjalin hubungan sosial melalui internet merupakan alasan utama yang dilakukan oleh khalayak dalam mengakses media. Hal ini merupakan salah satu hal yang tidak dapat diperoleh dari penggunaan media kovensional. Maka dari itu, tidak heran bahwa kehadiran internet dan media sosial menjadi cukup fenomenal.

Media sosial saat ini dapat dipakai untuk menunjang aktivitas penggunanya, beberapa perusahaan, dan juga individu juga menggunakan media sosial untuk melancarkan bisnisnya (Ardianto 2011 : 114).

Pada pembahasan kali ini, hasil analisis penulis menemukan bahwa media sosial merupakan sebuah media yang saat ini diminati banyak orang untuk mencari informasi dan menunjukkan eksistensinya. Berikut ini beberapa fungsi media sosial menurut Usman Hamid (2011):

(a) Sebagai alat informasi;

Setiap orang dapat mencari segala informasi atau menerima informasi dengan mudahnya.

(b) Sebagai alat interaksi;

Media sosial sebagai alat interaksi tidak hanya sekedar koneksi antar jaringan situs ataupun akun, melainkan juga interaksi kreatif yang dilakukan pengguna dalam bertukar informasi. Orang tidak hanya mendapatkan informasi tapi juga memiliki kesempatan untuk menanggapi sebuah informasi.

(c) Sebagai alat partisipasi

Media sosial sebagai alat berpartisipasi dalam sebuah gerakan.

Berdasarkan penjelasan diatas, penulis menemukan bahwa PT Eannovate menjalankan salah satu fungsi yang dimiliki oleh media sosial yaitu sebagai alat informasi. Selain itu, fungsi media sosial sebagai alat interaksi juga turut dipakai 
Rosliana dan Riris Loisa: Strategi Cyber Public Relatons dalam Memanfaatkan Media Sosial untuk Membangun Citra Perusahaan

oleh PT Eannovate dalam menyebarkan dan berinteraksi secara langsung dengan audience.

Selain itu, hasil analisis penulis juga menemukan bahwa pemanfaatan media sosial pun tidak hanya dirasakan oleh perusahaan saja. Seperti yang dikatakan oleh salah satu informan, Daud Julio, bahwa ia mendapatkan pekerjaannya di PT Eannovate Creative Technology melalui media sosial yaitu Facebook. Berdasarkan keterangan tersebut. penulis menemukan bahwa fungsi media sosial sebagai alat informasi berhasil membuat audience menemukan PT Eannovate.

Kehadiran media sosial nyatanya diterima dan disambut baik oleh masyarakat di era sekarang ini, apalagi media sosial memberikan akses yang mudah dan tidak terbatas sehingga masyarakat bisa mendapatkan informasi kapan saja dan dimana saja (Ardianto, 2011:165).

Menurut Daud sebagai seorang karyawan yang mendapatkan pekerjaannya melalui Facebook, media sosial menjadi wadah yang memudahkan perusahaan untuk mencari perhatian dan mendekati sasaran pasar. Hal ini dikarenakan cakupan media sosial yang terbuka dan tidak terbatas. Serupa dengan Daud, Isabela Beatrix pada awalnya menemukan Eannovate saat mencari lowongan magang. Setelah itu ia diterima bekerja sebagai karyawan magang dan sekarang menjabat sebagai salah satu karyawan di bidang graphic designer di PT Eannovate. Penulis menemukan bahwa fungsi media sosial sebagai alat informasi juga berhasil digunakan oleh PT Eannovate dalam mendapatkan audience.

Isabela juga menambahkan bahwa ada dampak positif dan negatif juga yang ia lihat dari penggunaan media sosial PT Eannovate seperti yang diucapkan oleh Daud. Ia merasa bahwa dampak positif yang ia lihat dari penggunaan media sosial PT Eannovate adalah karakter media sosial yang informatif dan modern serta mudahnya akses dapat membuat perusahaan berbasis teknologi dan digital marketing seperti Eannovate memiliki keunggulan.

Kemudahan dan kecepatan dalam mengakses segala informasi melalui media sosial merupakan salah satu manfaat yang dirasakan. Apalagi jika target dari perusahaan sesuai. Isabela menambahkan bahwa audience yang merupakan generasi milenial merupakan salah satu target audience bagi perusahaan berbasis teknologi dan digital marketing seperti Eannovate.

Keberhasilan program PR bergantung pada siapa publiknya, bagaimana strategi yang digunakan, dapat tidaknya mempengaruhi perusahaan dalam membina hubungan baik dan dialog yang sehat agar perusahaan dan publiknya semakin dekat (diadaptasi dari Soemirat dan Ardianto, 2003:190-193).

Tugas utama dari seorang praktisi public relations adalah membangun hubungan baik dengan berbagai kalangan agar dapat membangun citra perusahaan yang baik, serta menangani atau menghadapi rumor, berita, dan kejadian yang tidak menyenangkan. Hal ini dapat diwujudkan oleh perusahaan dengan memanfaatkan media sosial.

Dalam penelitian ini, tujuan dari penulis adalah melihat pemanfaatan cyber public relations dalam media sosial bagi perusahaan. Berdasarkan hasil analisis dari wawancara narasumber yang penulis dapatkan, penggunaan media sosial merupakan salah satu langkah yang tepat dalam menjalankan strategi public relations. Meskipun hal ini masih terdapat sisi negatif dari kurang gencarnya promosi dan konten yang diberikan oleh perusahaan. 
Hal ini membuat PT Eannovate Creative Technology menggunakan media sosial sebagai wadah untuk melakukan promosi dan membangun citra perusahaan serta menjalin hubungan baik dengan khalayaknya.

Gambar 1. Instagram PT Eannovate Creative Technology

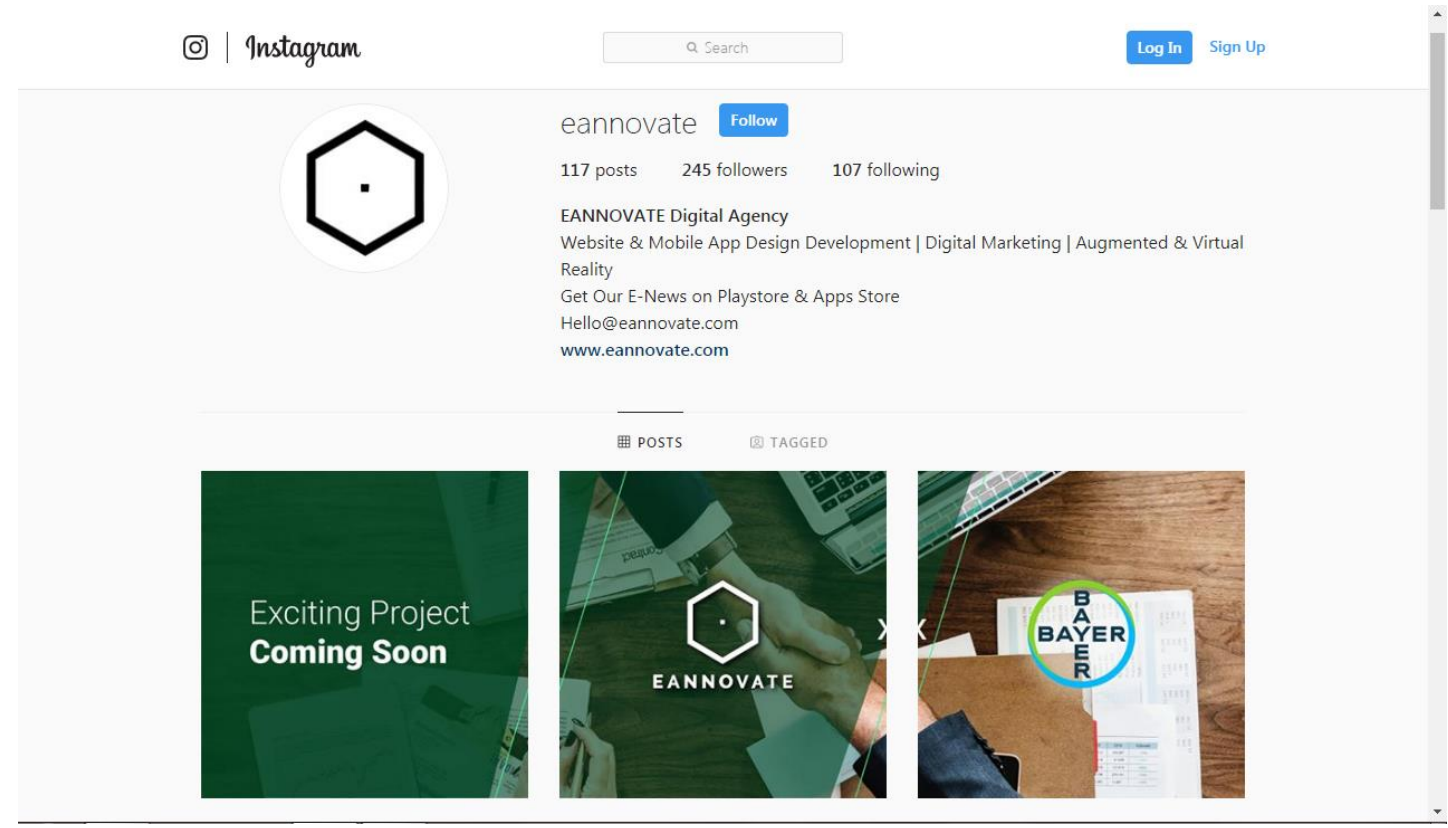

Sumber: https://www.instagram.com/eannovate/ (2018)

PT Eannovate Creative Technology memanfaatkan media sosial Instagram dan Facebook untuk memberikan informasi akan klien, jasa dan layanan yang disediakan, dan juga info seputar berita teknologi kreatif. Hal ini meyakinkan penulis dalam menemukan kesamaan antara karakteristik media sosial yang nyatanya diterima dan disambut baik oleh masyarakat di era sekarang ini, dengan fungsi penggunaan media sosial bagi PT Eannovate Creative Technology.

Gambar 2. Facebook PT Eannovate Creative Technology

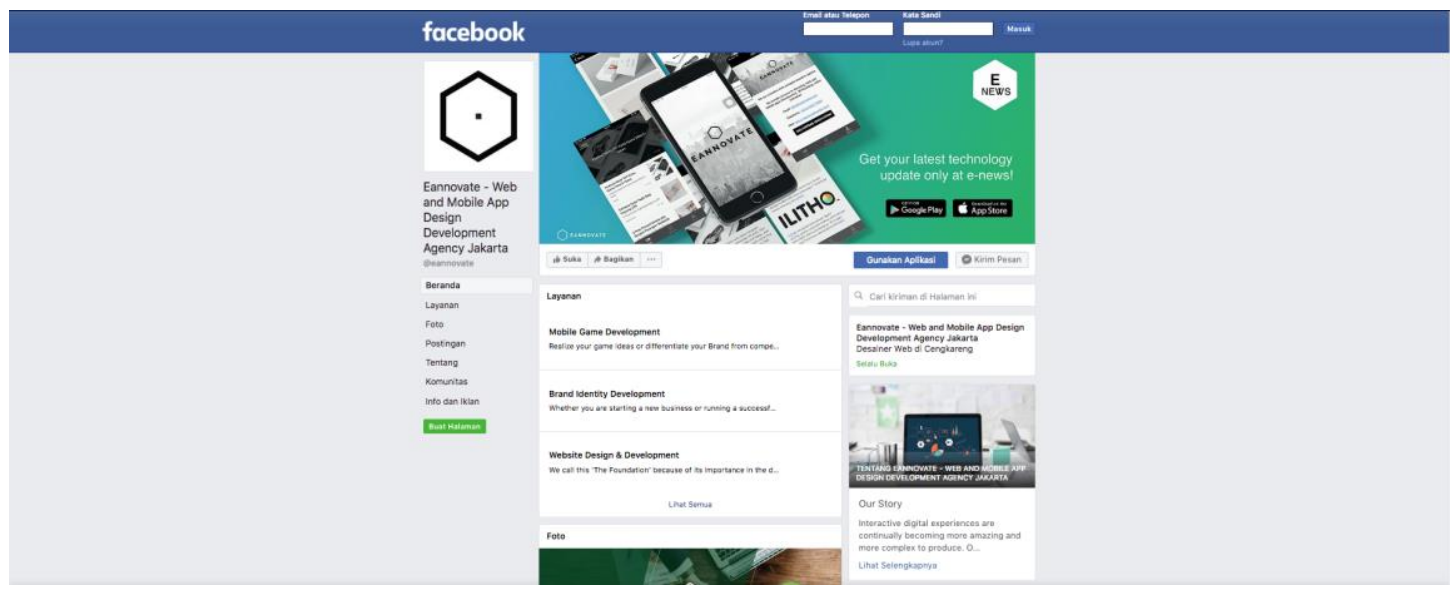

Sumber: https://www.instagram.com/p/BijHCbZngQE/ (2018) 
Rosliana dan Riris Loisa: Strategi Cyber Public Relatons dalam Memanfaatkan Media Sosial untuk Membangun Citra Perusahaan

\section{Simpulan}

Menurut penulis,salah satu strategi yang tepat yang diambil oleh PR perusahaan adalah memanfaatkan media sosial sebagai salah satu platform untuk memperkenalkan dan menyebarluaskan informasi yang berkaitan dengan perusahaan kepada masyarakat. Hal ini terjadi pula pada PT Eannovate Creative Technology yang memanfaatkan media sosial sebagai platform-nya dalam memberikan informasi kepada masyarakatnya adalah PT Eannovate Creative Technology.

Strategi public relations yang dilakukan oleh PT Eannovate Creative Technology dapat diselaraskan dengan pendapat yang diutarakan oleh Ronald D. Smith dalam penjelasannya mengenai stra

Dalam memanfaatkan media sosial, PT Eannovate Creative Technology menggunakan Facebook dan Instagram sebagai sarana dan wadah untuk membangun citra perusahaan. Citra perusahaan yang positif dapat terbentuk karena adanya keterlibatan antara perusahaan dan masyarakat dalam melakukan pertukaran informasi.

Saran dari penulis adalah agar praktisi di bidang komunikasi, khususnya sebagai praktisi public relations di perusahaan berbasis teknologi seperti PT Eannovate Creative Technology dapat terus mengembangkan konten yang akan disebarkan dalam media sosial agar target dan strategi yang dimiliki mencapai dampak bagi perusahaan yaitu citra positif di mata masyarakat.

\section{Ucapan Terima Kasih}

Ucapan terima kasih penulis tujukan kepada seluruh pihak yang telah membantu selama proses penelitian ini berlangsung sampai dengan selesainya. Terutama kepada seluruh narasumber yang bersedia memberikan kerjasamanya dalam penelitian ini.

\section{Daftar Pustaka}

Ardianto, Elvinaro \& Soemirat, S. (2003). Dasar-dasar Publik Relation. Bandung: Remaja Rosdakarya.

Friedman, Thomas L. (2006) The World is Flat : Sejarah singkat abad ke-21. Jakarta: Dian Rakyat

Smith, Ronald D. (2005). Strategic Planning for Public Relations. Second Edition. NewJersey: Lawrence Erlbaum Associates

Yin, Robert K. (2011) Studi Kasus: Desain dan Metode. Jakarta: Rajagrafindo Persada

Hamid, Farid \& Budianto, H. (2011). Ilmu Komunikasi Sekarang dan Tantangan

Masa Depan. Jakarta: Prenada Media Group $<$ https://www.instagram.com/eannovate/> $<$ https://www.instagram.com/p/BijHCbZngQE/> 